\title{
Vacuum microcasting of 2-methacryloyloxyethyl phosphorylcholine polymer for stable cell patterning
}

Nobuyuki Tanaka ${ }^{\ddagger}, 1$ (i), Ryoji Sekine ${ }^{\ddagger}, 2$, Shun-ichi Funano', Asako Sato1, Núria Taberner Carretero ${ }^{2,3}$ (iD, Miki Ebisuya ${ }^{2,3}$ (iD \& Yo Tanaka*,1

${ }^{1}$ Laboratory for Integrated Biodevice, Center for Biosystems Dynamics Research, RIKEN, 1-3 Yamadaoka, Suita, Osaka 565-0871, Japan; ${ }^{2}$ Laboratory for Reconstitutive Developmental Biology, Center for Biosystems Dynamics Research, RIKEN, 2-2-3 Minatojima-Minamimachi, Chuo-ku, Kobe, Hyogo 650-0047, Japan; ${ }^{3}$ European Molecular Biology Laboratory (EMBL) Barcelona, Dr. Aiguader 88, 08003 Barcelona, Spain; *Author for correspondence: yo.tanaka@riken.jp; ${ }^{\ddagger}$ Authors contributed equally

BioTechniques 69: 171-177 (September 2020) 10.2144/btn-2020-0052

First draft submitted: 21 April 2020; Accepted for publication: 5 June 2020; Published online: 25 June 2020

\section{ABSTRACT}

This study demonstrates the rapid fabrication and utility of 2-methacryloyloxyethyl phosphorylcholine (MPC) polymer film for cell patterning. The film was obtained on a cell culture surface by microcasting MPC polymer ethanol solution into a degassed polydimethylsiloxane mold with a desired pattern. After removal of the mold, 293AD cells were cultured on the surface of the polymer film with the patterned microstructures. Patterned cell adhesion restricted by the film was successfully maintained during at least a 168-h cultivation. The microcast MPC polymer film can be prepared rapidly and used for efficient long-term cell confinement.

\section{GRAPHICAL ABSTRACT}

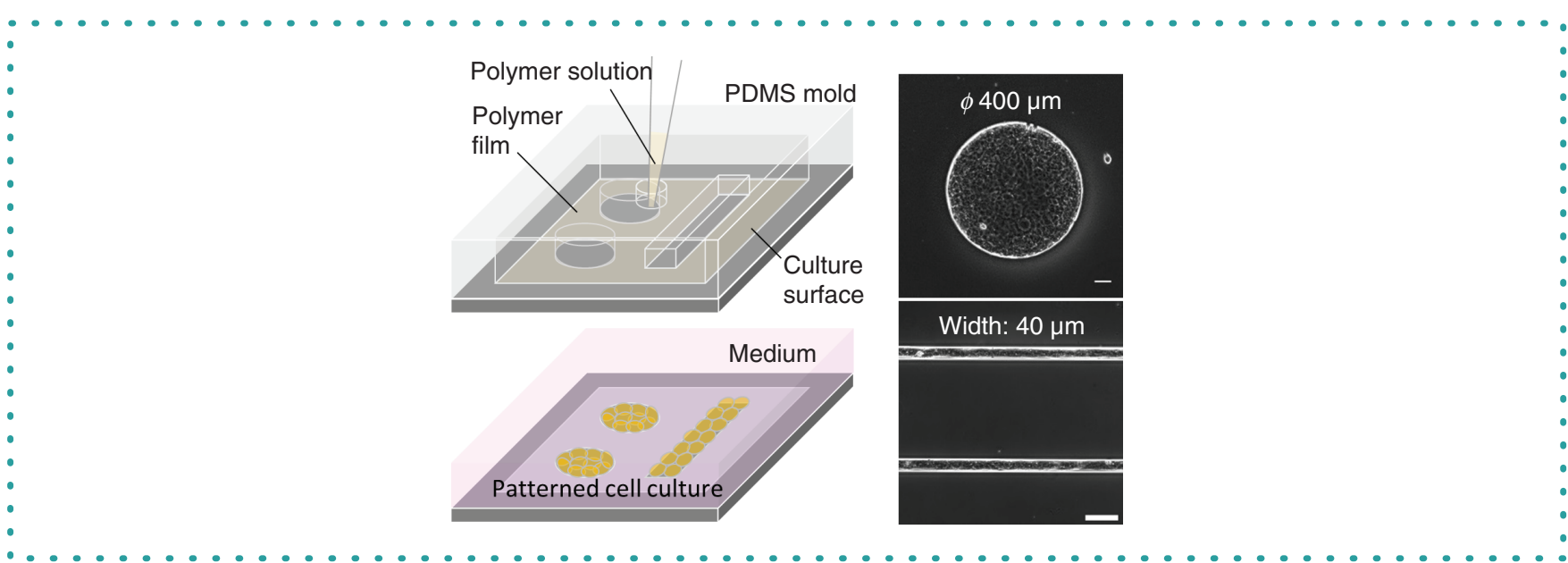

\section{VIDEO ABSTRACT}

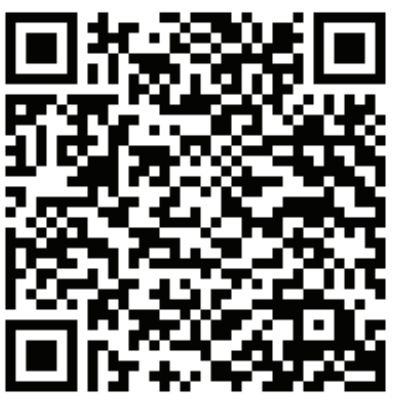

\section{KEYWORDS}

2-methacryloyloxyethyl phosphorylcholine polymer $\bullet$ cell patterning • microcasting • polydimethylsiloxane $\bullet$ rapid fabrication 
Cell micropatterning techniques are often used for in vitro biological experiments [1]. Microscopy of cells is basic in biological studies; however, cell stacking due to high proliferation rates and cell migration out of the field of view often prevent good quantitative measurements from being obtained. Well-aligned cell patterning techniques are useful for avoiding these issues and they ensure high-throughput analysis [2]. For instance, in neural cell studies, axonal guidance by micropattern surface modifications provides the best environment for axon length measurements [3,4]. Because spatial confinement directly affects stem cell fate, patterned cell culture is also an important technique in stem cell and developmental biology studies $[5,6]$.

Because cells adhere to culture surfaces via an extracellular matrix consisting of proteins such as fibronectin and polysaccharides such as hyaluronic acid [7-11], the spatial control of cell-adhesive and nonadhesive substrate areas is an important approach to obtain cell patterning. In this method, cells are seeded on a cell culture surface with a desired pattern consisting of cell-adhesive regions surrounded by a nonadhesive area, where cells cannot attach or migrate. Reports have been made for in vitro systems that divide the areas between cell adhesion and nonadhesion [12] by such approaches as surface chemical modification [13], microcontact printing [14,15], liquid interfaces [16], and microfluidic systems [17,18].

There are two main approaches to add functionalities to the surface: cell adherence and cell repellency. In the former, the surface is immobilized with a molecule, for example fibronectin; however, such an adhesive molecule generally stimulates cells biochemically [19]. The cell repellency approach is therefore preferred for distinguishing between biochemical and geometrical stimulations. For example, the patterned differentiation of stem cells can be compared using the difference of stimulations between biochemical (microcontact printing of a cell-adhesive molecule) [20] and geometrical (microcasting of cell repellent) [6] approaches.

To prevent the adsorption of adhesive molecules, most substances that suppress protein adsorption can be used as cell repellent materials [21,22]; for example, polyethylene glycol [23], ethylene glycol [24], polyacrylamide, [25] and albumin [26-28]. In previous studies $[6,29]$, an agarose microstructure placed on a culture surface was used to achieve cell patterning. This microstructure was formed from a negative mold of degassed polydimethylsiloxane (PDMS) with a desired pattern of microchannels. The degassed PDMS can generate a vacuum pressure, resulting in a driving force to introduce liquid into a microchannel [30]. Once the PDMS mold is obtained, the fabrication process is quite simple and does not need any special apparatus. Conversely, although agarose is a common material in biological laboratories and its biocompatible properties are well known [31], the fabrication time is generally long due to the dehydration process which requires more than 1-2 days to ensure stability of the agarose microstructure [6,29].

Here we employed 2-methacryloyloxyethyl phosphorylcholine (MPC) polymer instead of agarose. The MPC polymer, which has a chemical structure similar to a phospholipid cell membrane, has often been used for reducing protein adsorption by hydration of the polymer and enhancing biocompatibility on medical devices [32]. MPC cell repellency is effective toward most adhesive cells, and cell patterning using MPC polymer has been shown to be stable for over 1 week [33]. However, the previously reported approach is a lightbased method requiring a photolabile linker that is not easily available. This problem can be addressed by using a MPC polymer microcasting method. Furthermore, the MPC polymer is commercially available as an ethanol solution ready for surface coating - unlike agarose, which is insoluble in ethanol [34]. Because ethanol evaporates faster than water, the fabrication time is expected to be reduced. This study verified the suitability of microcast MPC polymer film for cell patterning from the viewpoints of fabrication accessibility and continuous microscopy (i.e., live cell imaging).

\section{Materials \& methods}

\section{Fabrication of PDMS micromolds}

The fabrication procedure was based on previous papers [6,29]. Briefly, PDMS micromolds were prepared by casting from negative photoresist (SU-8 2035, Nippon Kayaku, Tokyo, Japan) on a Si-wafer with a desired pattern. PDMS and a curing agent (Sylpot 184 W/C, Dow Corning Toray, Tokyo, Japan) were mixed at a ratio of 10:1, poured into the Si-wafer mold and cured at $80^{\circ} \mathrm{C}$ for $3 \mathrm{~h}$. The cured PDMS was peeled off, trimmed, and punched out with a 2-mm-diameter through hole in the center of the desired pattern as an application port, resulting in a micromold for casting the MPC polymer film.

\section{Microcasting of MPC polymer}

The surface of the PDMS micromold was cleaned using mending tape (MP-18, Sumitomo 3M, Tokyo, Japan), and the mold was sterilized by immersing in $70 \%$ ethanol aqueous solution. After the solution was evaporated, the mold was put on the glass-base part (diameter $12 \mathrm{~mm}$ ) of a 35-mm culture dish (3971-035, Iwaki, Shizuoka, Japan). The mold and dish were placed in a vacuum container and degassed for $1 \mathrm{~h}$. Within 3 min after degassing, $15 \mu$ of $3 \%$ MPC polymer (LIPIDURE ${ }^{\circledR}$-CM5206, NOF Corp., Tokyo, Japan) ethanol solution was added through the hole in the PDMS mold to the area between the mold and the glass dish. This was kept at room temperature until the solution was evaporated, and then the PDMS mold was gently removed from the dish to reveal the MPC polymer film with microstructures. The obtained MPC polymer microstructures were observed with a phase-contrast microscope (IX71, Olympus, Tokyo, Japan). The glassbase dish containing the MPC film with microstructures was sterilized by exposing to UV light for $1 \mathrm{~h}$ prior to use. 


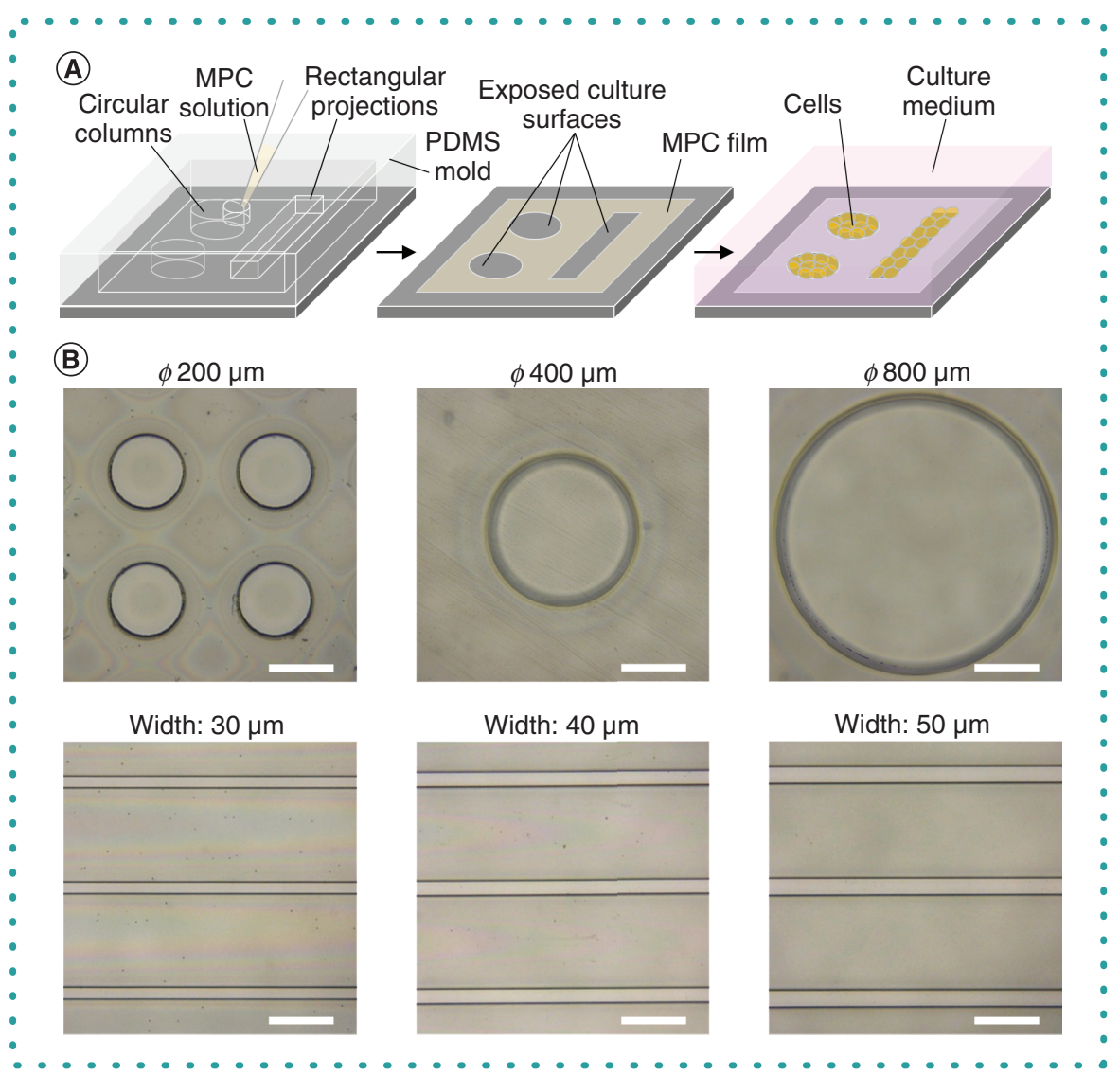

Figure 1. Rapid fabrication of MPC polymer film for cell patterning. (A) Fabrication flow. The ethanol solution of MPC polymer was introduced into the degassed PDMS mold by vacuum pressure. After removal of the mold, the dried MPC polymer film was revealed with the exposed culture surfaces. The cells would attach only on the exposed culture surface. (B) Various shapes of exposed culture surfaces surrounded with MPC polymer film. Scale bars: $200 \mu \mathrm{m}$.

MPC: 2-methacryloyloxyethyl phosphorylcholine; PDMS: Polydimethylsiloxane.

\section{Cell culture}

Human embryonic kidney cell line 293AD (Cell Biolabs, CA, USA), derived from parental HEK293 cells, was used. Cells were maintained in Dulbecco's modified Eagle medium/F12 medium containing $10 \%$ fetal bovine serum at $37^{\circ} \mathrm{C}$ with $5 \% \mathrm{CO}_{2}$. To remove bubbles caught in the microstructure pattern in advance of cell seeding, $2 \mathrm{ml}$ of medium at $37^{\circ} \mathrm{C}$ was added to the glass-base region of the dish, and the dish was chilled at $4^{\circ} \mathrm{C}$ for $1 \mathrm{~h}$. After this, the medium in the dish was removed and $2.0 \times 10^{5}$ cells suspended in $150 \mu l$ of medium were seeded onto the glass-base region. After $1 \mathrm{~h}$ incubation at $37^{\circ} \mathrm{C}$, the medium was gently exchanged with $2 \mathrm{ml}$ of fresh medium. In the case of long-term cultivation, the medium was then exchanged every $24 \mathrm{~h}$ with fresh medium.

\section{Staining cells}

Cell nuclei were stained with Hoechst 33342 (H3570, Thermo Fisher, MA, USA) and propidium iodide (PI; P3566, Thermo Fisher) for a cell viability assay modified from the supplier's protocols. Hoechst 33342 and PI aqueous solutions were added to the medium (final concentrations: $10 \mu \mathrm{g} / \mathrm{ml}$ for Hoechst and $1 \mu \mathrm{g} / \mathrm{ml}$ for PI) at 24 or $168 \mathrm{~h}$ after seeding cells. 90 min after incubation, the medium containing both solutions was exchanged with fresh medium, prior to microscopic observation of cultured cells using a scanning laser confocal microscope (LSM 780, Zeiss, Oberkochen, Germany) with bright-field and fluorescent (Hoechst or PI) views. Cell number was counted by using the Hoechst images with image processing software ImageJ [35].

\section{Results \& discussion}

\section{Confirmation of MPC polymer film patterning}

MPC polymer films with circular column and line patterns were successfully fabricated on the glass-base dish by microcasting with a degassed PDMS mold (Figure 1A). The diameters of the circular shape were 200, $400 \mathrm{or} 800 \mu \mathrm{m}$ and the widths of the line shape were 30 , 40 or $50 \mu \mathrm{m}$ (Figure 1B). Several variations of incubation time, from $1 \mathrm{~h}$ to overnight, were assessed. A drying time of $1 \mathrm{~h}$ was insufficient 
(A)

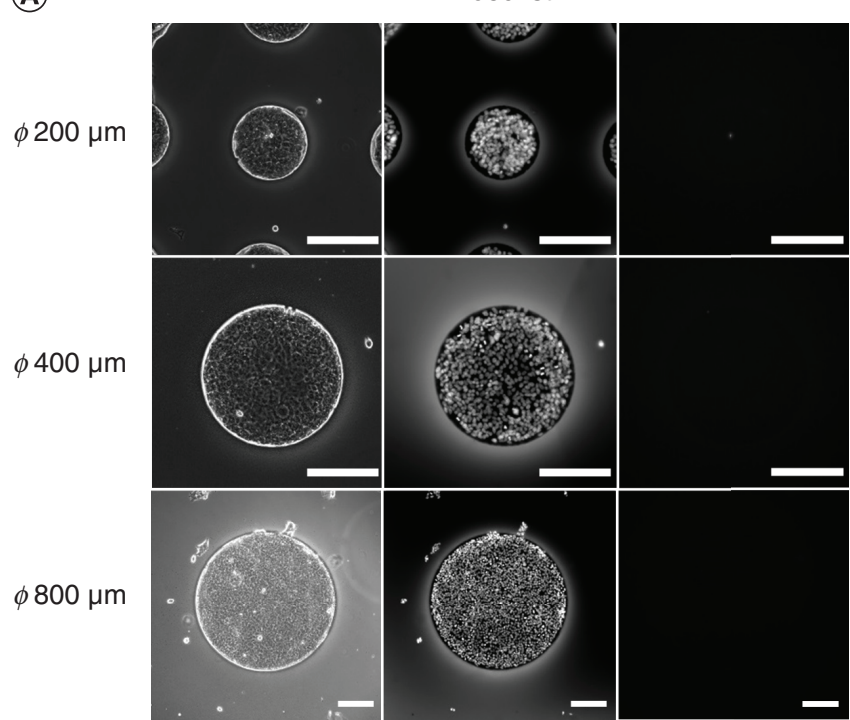

(D)

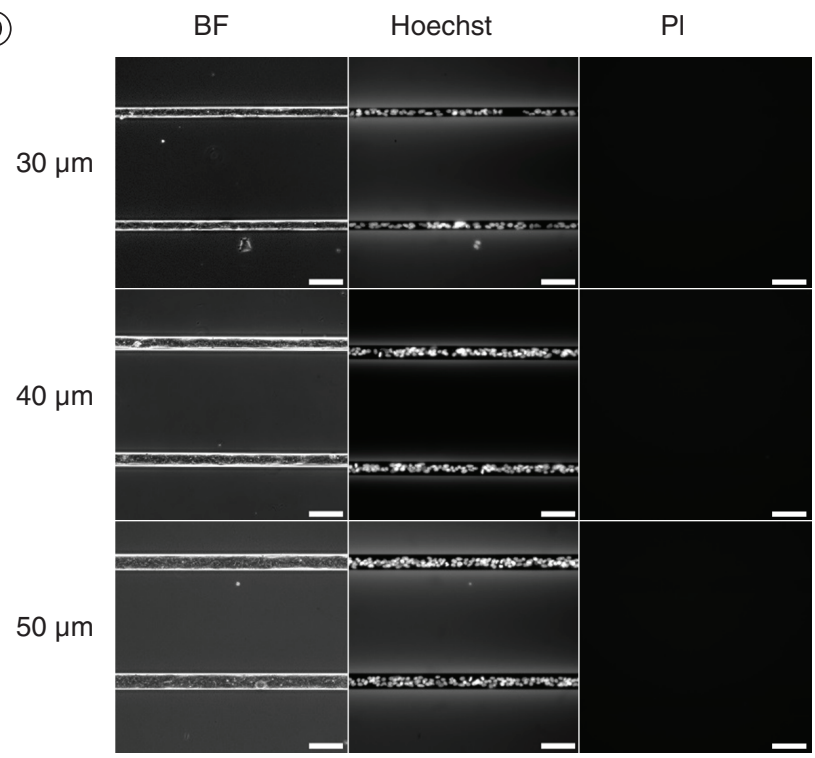

(B)

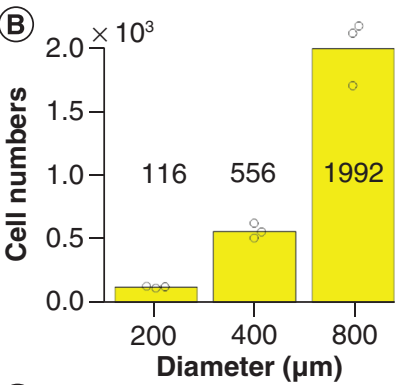

(C)

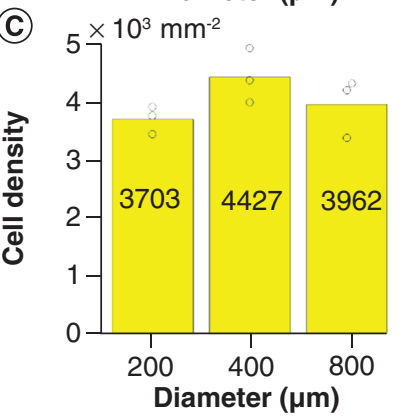

(E)
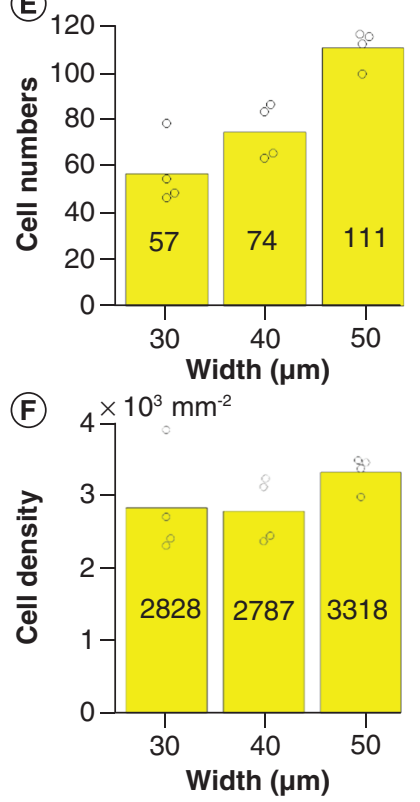

Figure 2. Microscopic image, cell numbers and density of 293AD cells cultivated for $24 \mathrm{~h}$ on circular (A-C) and line (D-F) patterns. Scale bars: (A) $200 \mu \mathrm{m}$ and (D) $50 \mu \mathrm{m}$. Bars and circles in graphs indicate mean and analyzed values. (B) and $(C) n=3$. $(E)$ and $(F) n=4$.

and the patterns collapsed, but no collapse was observed for drying times over $3 \mathrm{~h}$. Thus the desired patterns can be prepared in the MPC polymer film even on the day of cell seeding, comparing favorably with the 2-day drying time for agarose casting [6,29].

\section{Observation of cells}

To confirm whether cellular attachments were limited to the formed patterns, 293AD cells were seeded with confluent density onto a dish with circular or line-shaped patterns. These cells were specifically selected for two reasons: their firmer attachment to a culture surface compared with HEK293 cells [36]; and their previous use for the analysis of cell-cell communication via diffusible molecules [37]. Therefore, these cells can be a benchmark for cell patterning by nonchemically stimulating surface repulsion of strongly adhering cells. In the case of the circular shape, cells were successfully attached to the area of the cell culture surface surrounded by the MPC polymer film and only a few cells were attached on the MPC polymer region at $24 \mathrm{~h}$ after cell seeding (Figure 2A). Two types of nucleus staining 
(A)

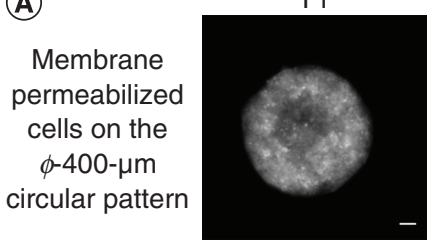

(B)
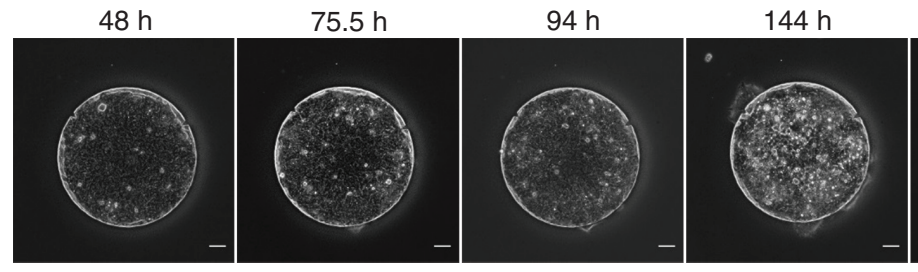

$168 \mathrm{~h}$

$\phi 400 \mu \mathrm{m}$

(C)

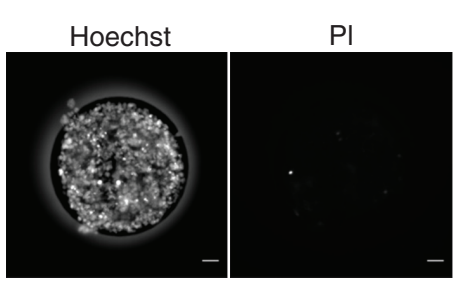

Merged

(Hoechst and PI)

$\phi 400 \mu \mathrm{m}$ at $168 \mathrm{~h}$

(D)
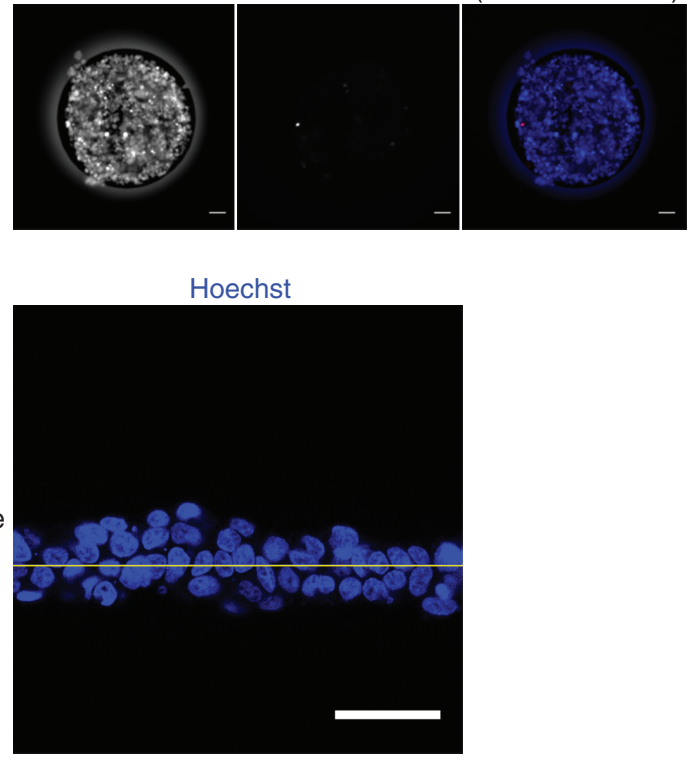

$X-Y$ view on the

40- $\mu \mathrm{m}$-width line pattern at $96 \mathrm{~h}$

Z-slice on the yellow line

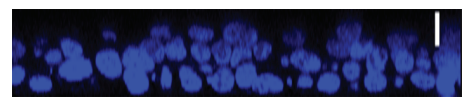

Figure 3. Microscopic images of 293AD cells cultured on surfaces surrounded with the MPC polymer film. (A) Nucleus distribution of cells stained with $\mathrm{PI}$ after the permeabilization of cell membrane. (B) Bright-field views of cells cultivated for $48,75.5,94,144$ and $168 \mathrm{~h}$ on the $400-\mu \mathrm{m}$-diameter circular pattern. (C) Nucleus distributions of cells cultivated for $168 \mathrm{~h}$. Hoechst (left image) and PI (center image) nucleus staining. (D) Confocal microscopic images of cells cultivated on the $40-\mu \mathrm{m}$-width line pattern for $96 \mathrm{~h}$. Scale bars: (A-C) and horizontal scale in (D) $50 \mu \mathrm{m}$. Vertical bar in (D) $20 \mu \mathrm{m}$. PI: Propidium iodide.

with Hoechst and PI without permeabilization of the cell membrane were performed at $24 \mathrm{~h}$ after cell seeding to visualize the total number of cells and the number of dead cells, respectively (Figure 2A). Because only dead cells have sufficient membrane permeability to PI dyes (Figure $3 \mathrm{~A}$ ), this staining allowed the dead cells to be distinguished from the total number of cells stained with Hoechst. None or only a few dead cells were observed (Figure 2A image for $200 \mu \mathrm{m}$ diameter and Figure 3C), so this method was postulated to have almost no effect on cell viability. The total number of cells stained with Hoechst was counted (Figure 2B) and the density of cells in the area of the circular shape was calculated (Figure 2C). As the diameter of the circular shape increased, the total number of cells also increased (Figure 2B); the cell density for each diameter size was around 4000 cells $/ \mathrm{mm}^{2}$ ( $p=0.1479$, Kruskal-Wallis test) (Figure 2C).

To assess the sustainability of the cell pattern, the cells were cultivated on the $400-\mu \mathrm{m}$-diameter circular pattern for a longer duration (7 days). Cells were observed every $24 \mathrm{~h}$ immediately after fresh medium exchange (Figure 3B). Confinement of cells was maintained on the circular pattern during the 7-day cultivation, with only a few cells migrating outside the circular pattern in observations at 144 
and $168 \mathrm{~h}$ (Figure 3B). Thus the MPC polymer film was able to stably block cellular adhesion in the medium for 7 days. Hoechst and PI staining revealed high cell survival at $168 \mathrm{~h}$ (Figure $3 \mathrm{C}$ ). These results showed that cells could survive in the circular pattern surrounded with the MPC polymer film and that the pattern of cells was maintained almost perfectly for at least 7 days.

In the case of the narrow line-shaped pattern, cells were also arranged in one to three rows along the line pattern at $24 \mathrm{~h}$; after Hoechst and PI staining, no dead cells were observed for any width condition (Figure 2D). The number of cells increased proportional to the width of the patterned line $\left(R^{2}=0.96\right.$, linear regression) (Figure 2E). Because the widths of the three line-shaped patterns were close to the sizes of a single cell and nucleus (roughly 30 and $10 \mu \mathrm{m}$, respectively), cells were aligned almost linearly. There was no significant difference in cell density among the three different line widths ( $p=0.2364$, Kruskal-Wallis test) (Figure 2F). To visualize the 3D distribution of cells, 96-h cultivations were further observed by z-stack confocal microscopy imaging of cell nucleus Hoechst staining (Figure 3D). Interestingly, cells piled up in three to four layers, but never spread onto the MPC polymer film. Thus the cells attached onto the line pattern formed a rod-like tissue structure by connecting to each other. This result indicates that the MPC polymer film showed strong cell repellency even when cells reached an 'overconfluent' state.

An MPC polymer film with microstructures was formed on a glass-base cell culture dish by a simple and fast casting fabrication. This method has good accessibility for biologists and will be applicable to various types of cellular patterning. The microcast film enabled long-term cell patterning of 293AD cells, which have strong attachment properties [36]. Because the cell adhesion area surrounded by the MPC polymer film is the intact cell culture substrate, this cell patterning approach is suitable for stationary microscopic observation, tissue engineering and cell morphology studies focusing especially on tissue morphology.

\section{Future perspective}

The use of microstructures to confine cells is spreading widely within biological experiments in developmental biology, mechanobiology and long-term microscopic observations. To date, various approaches for this purpose have been proposed, such as microcontact printing and microstencil methods. Because the developed approach, which combines an MPC polymer and microcasting, has good accessibility for biological laboratories and adaptability to mass production, the authors believe that it will become a standard technique for cell confinement. In particular, cell culture substrates with the MPC polymer structures are suitable for studies on chemical stimulations, including analysis of autocrine or paracrine effects on the confined cells. Additionally, because the MPC polymer has an anti-bacterial adhesion property, this approach can be used for bacterial patterning.

\section{Author contributions}

N Tanaka and R Sekine contributed equally to this work, and designed and performed the experiments. S Funano investigated the physicochemical properties of MPC polymer solution. N Tanaka and A Sato performed the microfabrication. N Taberner Carretero introduced the MPC polymer into the study. M Ebisuya and Y Tanaka supervised this study. N Tanaka, R Sekine and N Taberner Carretero wrote the manuscript with input from all authors.

\section{Financial \& competing interests disclosure}

Grant-in-Aid for Scientific Research on Innovative Areas (19H05338) from the Japan Society for the Promotion of Science, Japan; BDR organoid project, RIKEN, Japan. The authors have no other relevant affiliations or financial involvement with any organization or entity with a financial interest in or financial conflict with the subject matter or materials discussed in the manuscript apart from those disclosed.

C Kikuchi (MKC Consulting, Japan) provided writing assistance, funded by the BDR organoid project.

\section{Open access}

This work is licensed under the Attribution-NonCommercial-NoDerivatives 4.0 Unported License. To view a copy of this license, visit http://creativecommons.org/licenses/by-nc-nd/4.0/

\section{References}

Papers of special note have been highlighted as: $\bullet$ of interest

1. Théry M. Micropatterning as a tool to decipher cell morphogenesis and functions. J. Cell Sci. 123(24), 4201-4213 (2010).

- Detailed the importance of cell patterning techniques in biology.

2. Priest DG, Tanaka N, Tanaka Y, Taniguchi Y. Micro-patterned agarose gel devices for single-cell high-throughput microscopy of E. coli cells. Sci. Rep. 7(1), 1-7 (2017).

- Proposed the stable observation of $E$. coli by confining the target microorganisms.

3. Knöll B, Weinl C, Nordheim A, Bonhoeffer F. Stripe assay to examine axonal guidance and cell migration. Nat. Protoc. 2(5), 1216-1224 (2007).

- Proposed the application of cell patterning to axonal extension analysis.

4. Hayashi S, Inoue Y, Kiyonari H et al. Protocadherin-17 mediates collective axon extension by recruiting actin regulator complexes to interaxonal contacts. Dev. Cell. 30(6), 673-687 (2014).

5. Warmflash A, Sorre B, Etoc F, Siggia ED, Brivanlou AH. A method to recapitulate early embryonic spatial patterning in human embryonic stem cells. Nat. Methods 11(8), 847-854 (2014).

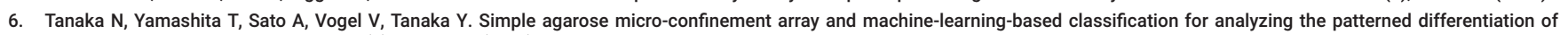
mesenchymal stem cells. PLoS ONE 12(4), e0173647 (2017).

7. Amstein CF, Hartman PA. Adaptation of plastic surfaces for tissue culture by glow discharge. J. Clin. Microbiol. 2(1), 46-54 (1975).

8. Curtis ASG, Forrester JV, McInnes C, Lawrie F. Adhesion of cells to polystyrene surfaces. J. Cell Biol. 97(5 pt I), 1500-1506 (1983). 
9. Yamada KM, Olden K. Fibronectins - adhesive glycoproteins of cell surface and blood. Nature 275(5677), 179-184 (1978).

10. Vogel V. Unraveling the mechanobiology of extracellular matrix. Annu. Rev. Physiol. 80(1), 353-387 (2018).

11. Evanko SP, Tammi MI, Tammi RH, Wight TN. Hyaluronan-dependent pericellular matrix. Adv. Drug Deliv. Rev. 59(13), 1351-1365 (2007).

12. Martinez-Rivas A, González-Quijano GK, Proa-Coronado S, Séverac C, Dague E. Methods of micropatterning and manipulation of cells for biomedical applications. Micromachines 8(12), 347 (2017).

13. Yamato M, Konno C, Utsumi M, Kikuchi A, Okano T. Thermally responsive polymer-grafted surfaces facilitate patterned cell seeding and co-culture. Biomaterials 23(2), 561-567 (2002).

14. Qin D, Xia Y, Whitesides GM. Soft lithography for micro- and nanoscale patterning. Nat. Protoc. 5(3), 491-502 (2010).

- Provides a microcontact printing approach which is an interesting counterpart method.

15. Singh AV, Mehta KK, Worley K, Dordick JS, Kane RS, Wan LQ. Carbon nanotube-induced loss of multicellular chirality on micropatterned substrate is mediated by oxidative stress. ACS Nano 8(3), 2196-2205 (2014).

16. Javaherian S, Li KJ, McGuigan AP. A simple and rapid method for generating patterned co-cultures with stable interfaces. BioTechniques 55(1), 21-26 (2013).

- Microfluidics-based cell patterning approach, the same as the present study.

17. Kaji H, Kawashima T, Nishizawa M. Patterning cellular motility using an electrochemical technique and a geometrically confined environment. Langmuir 22(25), 10784-10787 (2006).

- Microfluidics-based cell patterning approach, the same as the present study.

18. Shrirao AB, Hussain A, Cho $\mathrm{CH}$, Perez-Castillejos R. Adhesive-tape soft lithography for patterning mammalian cells: application to wound-healing assays. BioTechniques $53(5)$, $315-318$ (2012).

19. Watt FM, Huck WTS. Role of the extracellular matrix in regulating stem cell fate. Nat. Rev. Mol. Cell Biol. 14(8), 467-473 (2013).

20. Ruiz SA, Chen CS. Emergence of patterned stem cell differentiation within multicellular structures. Stem Cells 26(11), 2921-2927 (2008).

21. Funano S, Tanaka N, Tanaka Y. User-friendly cell patterning methods using a polydimethylsiloxane mold with microchannels. Dev. Growth Differ. 62(3), 167-176 (2020).

22. Singh AV, Patil R, Thombre DK, Gade WN. Micro-nanopatterning as tool to study the role of physicochemical properties on cell-surface interactions. J. Biomed. Mater. Res. Part A 101(10), 3019-3032 (2013).

- Method of liquid driving by degassed PDMS that led to the development of our method.

23. Khademhosseini A, Yeh J, Jon S et al. Molded polyethylene glycol microstructures for capturing cells within microfluidic channels. Lab Chip 4(5), 425-430 (2004).

- Interesting from the viewpoint of material for cell patterning, which is a hydrogel.

24. Singh AV, Sitti M. Patterned and specific attachment of bacteria on biohybrid bacteria-driven microswimmers. Adv. Healthc. Mater. 5(18), 2325-2331 (2016).

25. Moeller J, Denisin AK, Sim JY, Wilson RE, Ribeiro AJS, Pruitt BL. Controlling cell shape on hydrogels using liftoff protein patterning. PLoS ONE 13(1), 1-17 (2018).

- Interesting from the viewpoint of material for cell patterning, which is a hydrogel.

26. Singh AV, Gailite L, Vyas V et al. Rapid prototyping of nano- and micro-patterned substrates for the control of cell neuritogenesis by topographic and chemical cues. Mater. Sci. Eng. C. 31(5), 892-899 (2011).

27. Singh AV, Lenardi C, Gailite L, Gianfelice A, Milani P. A simple lift-off-based patterning method for micro- and nanostructuring of functional substrates for cell culture. J. Micromech. Microeng. 19(11), 115028 (2009).

28. Shen Y, Tanaka N, Yamazoe $\mathrm{H}$ et al. Flow analysis on microcasting with degassed polydimethylsiloxane micro-channels for cell patterning with cross-linked albumin. PLoS ONE 15(5), e0232518 (2020).

29. Tanaka N, Moriguchi H, Sato A et al. Microcasting with agarose gel via degassed polydimethylsiloxane molds for repellency-guided cell patterning. RSC Adv. 6(60), 54754-54762 (2016).

30. Hosokawa K, Sato K, Ichikawa N, Maeda M. Power-free poly(dimethylsiloxane) microfluidic devices for gold nanoparticle-based DNA analysis. Lab Chip 4(3), 181-185 (2004).

31. Zarrintaj P, Manouchehri S, Ahmadi Z et al. Agarose-based biomaterials for tissue engineering. Carbohydr. Polym. 187, 66-84 (2018).

32. Ishihara K, Nomura H, Mihara T, Kurita K, Iwasaki Y, Nakabayashi N. Why do phospholipid polymers reduce protein adsorption? J. Biomed. Mater. Res. 39(2), 323-330 (1998).

- Inspired our use of the MPC polymer for blocking cell adhesion.

33. Jang K, Sato K, Tanaka Y et al. An efficient surface modification using 2-methacryloyloxyethyl phosphorylcholine to control cell attachment via photochemical reaction in a microchannel. Lab Chip 10(15), 1937-1945 (2010).

34. Agar | The Merck Index Online. https://www.rsc.org/Merck-Index/monograph/m1446/agar?q=authorize

35. Schneider CA, Rasband WS, Eliceiri KW. NIH Image to ImageJ: 25 years of image analysis. Nat. Methods 9(7), 671-675 (2012).

36. FAQ: 293AD Cell Line | Cell Biolabs. https://www.cellbiolabs.com/faq/viral-expression-faq/adenoviral-cell-line

37. Sekine R, Shibata T, Ebisuya M. Synthetic mammalian pattern formation driven by differential diffusivity of Nodal and Lefty. Nat. Commun. 9(1), 1-11 (2018). 
